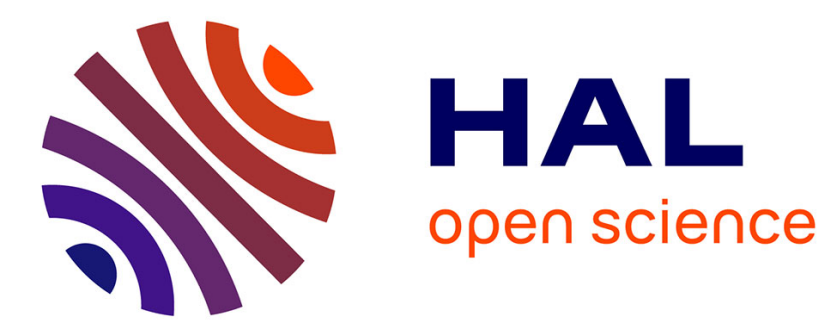

\title{
Effect of Anodic Oxidation on the Characteristics of Lattice-Matched AlInN/GaN Heterostructures
}

C Pietzka, A Denisenko, M Alomari, F Medjdoub, J-F Carlin, E Feltin, N Grandjean, E Kohn

\section{- To cite this version:}

C Pietzka, A Denisenko, M Alomari, F Medjdoub, J-F Carlin, et al.. Effect of Anodic Oxidation on the Characteristics of Lattice-Matched AlInN/GaN Heterostructures. Journal of Electronic Materials, 2008, 37, pp.616 - 623. 10.1007/s11664-008-0382-y . hal-03281235

\section{HAL Id: hal-03281235 \\ https://hal.science/hal-03281235}

Submitted on 8 Jul 2021

HAL is a multi-disciplinary open access archive for the deposit and dissemination of scientific research documents, whether they are published or not. The documents may come from teaching and research institutions in France or abroad, or from public or private research centers.
L'archive ouverte pluridisciplinaire HAL, est destinée au dépôt et à la diffusion de documents scientifiques de niveau recherche, publiés ou non, émanant des établissements d'enseignement et de recherche français ou étrangers, des laboratoires publics ou privés. 


\title{
Effect of Anodic Oxidation on the Characteristics of Lattice-Matched AllnN/GaN Heterostructures
}

\author{
C. PIETZKA ${ }^{1}$ A. DENISENKO,${ }^{1,3}$ M. ALOMARI ${ }^{1}$ F. MEDJDOUB,${ }^{1}$ \\ J.-F. CARLIN, ${ }^{2}$ E. FELTIN ${ }^{2}$ N. GRANDJEAN, ${ }^{2}$ and E. KOHN ${ }^{1}$ \\ 1.-Institute of Electron Devices and Circuits, Ulm University, $89081 \mathrm{Ulm}$, Germany. 2.-Ecole \\ Polytechnique Federale de Lausanne, 1015 Lausanne, Switzerland. 3.-e-mail: andrej. \\ denisenko@uni-ulm.de
}

The effect of anodic oxidation on the electronic characteristics of lattice-matched AlInN/GaN heterostructures was investigated using field-effect transistor (FET) structures with the gate areas in direct contact with the electrolytes. The gate surface of the FETs was subjected to anodic oxidation in $0.1 \mathrm{M} \mathrm{KOH}$. The oxidized heterostructures were analyzed by electrochemical impedance spectroscopy and by modeling the characteristics of the electrolyte-gate FETs and the energy-band diagram of the heterostructures. This analysis suggested that the anodic treatment induced a bulk oxidation of the AlInN barrier. The Fermi level at the oxidized AlInN surface was shifted deep into the bandgap. The oxidation led to a reduction of the carrier mobility and to partial depletion of the channel.

Key words: Lattice-matched, AlInN, anodic oxidation, surface states

\section{INTRODUCTION}

Recently the AlInN/GaN material system has become of interest for electronic applications due to its promising electronic properties, polarization effects, and high thermal stability. Significant progress in the growth of lattice-matched AlInN/GaN heterostructures has resulted in a polarizationinduced sheet charge density $n_{\mathrm{s}}>2 \times 10^{13} \mathrm{~cm}^{-2}$ in the two-dimensional (2D) channel in combination with a mobility $\mu>1000 \mathrm{~cm}^{2} / \mathrm{V}$ s at room temperature. ${ }^{1,2}$ Lattice matching at the AlInN/GaN interface can be achieved at $17 \%$ indium content in the AlInN barrier, which leads to a stress-free structure. $^{3}$ The stress-free structure and the high current densities make AlInN/GaN heterostructures an ideal candidate for high-power and high-temperature applications. For example, the AlInN/GaN heterostructure has shown an extraordinary temperature stability, ${ }^{4,5}$ which has been demonstrated by transistor operation at $1000^{\circ} \mathrm{C}$ in vacuum. ${ }^{4}$

(Received September 5, 2007; accepted January 3, 2008)
Despite this ceramic-like stability at high temperatures, the surface of the AlInN barrier layer could be subjected to oxidation and etching in strong acidic and alkaline electrolytes. ${ }^{6,7}$ However, no effect of the chemical treatment on the electronic properties of the heterostructures has been investigated yet. The information on the morphological and electronic characteristics of the oxidized barrier layers is needed to assess surface trapping and charging effects in high-electron-mobility transistors (HEMTs). Besides, oxidation of III-nitride materials may improve the characteristics of Schottky gate diodes. For instance, the leakage current of Schottky diodes on bulk-doped GaN layers could be strongly suppressed by oxidation due to blocking of dislocation-related defect paths. ${ }^{8}$

The oxidized AlInN/GaN heterostructures could also be used for chemical sensing devices, similar to the other III-nitrides and their compounds. ${ }^{9-14}$ An interesting aspect related to this application field might be a low density of stress-induced defects expected for the lattice-matched heterostructures. This particular characteristic could possibly improve the stability of AlInN surface against corrosion in electrolytes, as it is well known that the 
chemical limits of III-nitrides depend very much on their crystalline quality. ${ }^{15-17}$

A prerequisite of ion-sensing FETs on III-nitride materials is the presence of surface oxides bonds, ${ }^{10,18}$ which can be due to native oxidation in the atmosphere ${ }^{19}$ or induced by processing. However, chemical modification of the heterostructure surface may also induce charged electronic states which could pin the surface Fermi level and also affect the carrier transport in the $2 \mathrm{D}$ channel. In this paper we present our results on the effect of anodic oxidation in $0.1 \mathrm{M} \mathrm{KOH}$ electrolyte on the electronic properties of lattice-matched AlInN/GaN heterostructures. The anodic polarization of the heterostructure surface could also be related to the operation of ion-sensitive FETs under various bias conditions. Therefore, the evolution of the barrier and the channel characteristics under oxidation could be also useful to assess the performance of AlInN/GaN-based chemical sensors. In our study we investigated the effect of oxidation using the FET structures with gate areas in direct contact with electrolytes. The advantage of these structures is that they enable one to analyze the electrical equivalent circuit of the AlInN-electrolyte interface and to evaluate the transport properties in the $2 \mathrm{D}$ channel at the same time. The obtained results and the described methodology of the heterostructure evaluation could be used to optimize the oxidation processes of AlInN/GaN material for microwave HEMTs and chemical sensor applications.

\section{EXPERIMENTAL}

The lattice-matched $\operatorname{In}_{0.17} \mathrm{Al}_{0.83} \mathrm{~N} / \mathrm{GaN}$ heterostructures used in these experiments were grown by metalorganic chemical vapor deposition (MOCVD) on sapphire substrates with a thickness of the AlInN barrier layer of approximately $10 \mathrm{~nm}$. Details of the growth technique can be found elsewhere. ${ }^{1,4,20}$ The sheet charge density $n_{s}$ of the electron gas in the $2 \mathrm{D}$ channel was $2.6 \times 10^{13} \mathrm{~cm}^{-2}$, obtained from Hall measurements. The Hall mobility $\mu_{\mathrm{H}}$ at room temperature was $950 \mathrm{~cm}^{2} / \mathrm{V}$ s. A set of FET macrostructures with gate areas open for contact with electrolytes was fabricated on these heterostructures, as shown by the schematic cross section of a single device structure in Fig. 1. The mesa was defined by dry etching in argon plasma. $\mathrm{A} \mathrm{Ti} / \mathrm{Al} / \mathrm{Ni} / \mathrm{Au}$ sequence was used for ohmic contact metallization, following by rapid thermal annealing of the deposited metallization at $890^{\circ} \mathrm{C}$ in $\mathrm{N}_{2}$ atmosphere for $60 \mathrm{~s}$. The gate areas of the FET were formed using a PTFE (Teflon) adhesive tape with a perforated opening, resulting in a gate length $L_{\mathrm{G}}$ of $0.5 \mathrm{~mm}$ and a gate width of $1.6 \mathrm{~mm}$.

The electrochemical experiments were performed in a three-electrode glass cell with a platinum counterelectrode and a saturated calomel (SCE, $V_{\mathrm{SCE}}=+242 \mathrm{mV}$ versus normal hydrogen electrode) reference electrode. The fabricated structures were

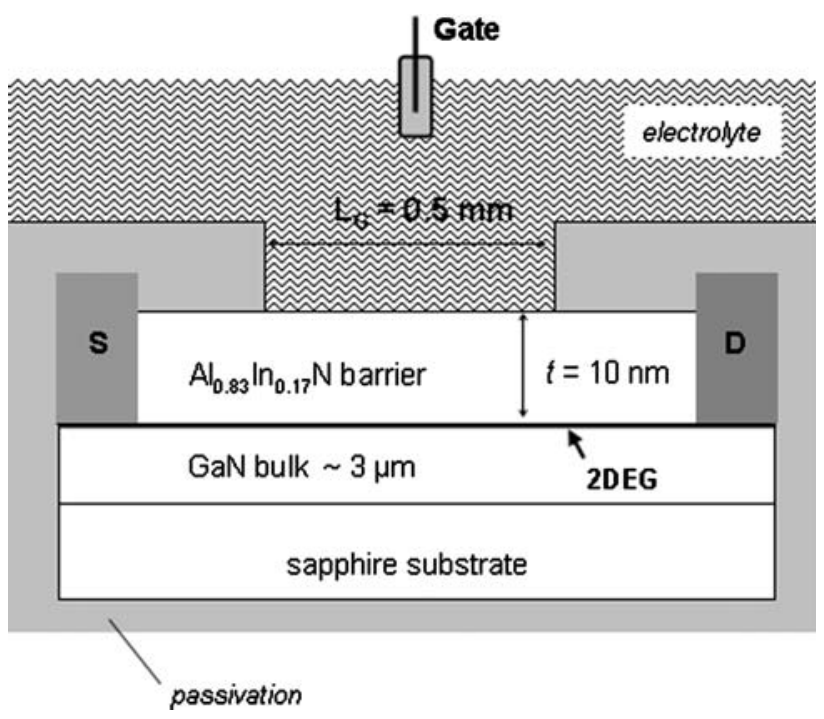

Fig. 1. Schematic cross section of an ion-sensitive FET on an AllnN/ GaN heterostructure.

analyzed in $0.1 \mathrm{M} \mathrm{H}_{2} \mathrm{SO}_{4}$ and $0.1 \mathrm{M} \mathrm{KOH}$ electrolytes. In the electrode mode (cyclic voltammetry and impedance spectroscopy measurements), the source and drain contacts of the FETs were short-circuited to achieve a constant potential along the channel and connected with the working electrode input of the potentiostat. Cyclic voltammetry and electrochemical impedance spectroscopy measurements were performed using a PARSTAT 2273 potentiostat (Princeton Applied Research). In the FET mode, the drain and the gate biases were controlled by Keithley 2420 and Keithley 238 source meters. The source-to-gate potential was adjusted to the potential of the SCE reference electrode using a personal computer (PC)-controlled Keithley 2000 electrometer. All measurements were performed in a grounded Faraday cage with the solutions deairated by nitrogen gas flow.

\section{RESULTS AND DISCUSSION}

\section{As-Grown Surface}

An atomic force microscopy (AFM) image of the as-grown surface is shown in Fig. 2a. The surface roughness by AFM was approximately $0.8 \mathrm{~nm}$ (RMS). The hole-like structures on the surface could be related to the presence of dislocation defects. The cyclic voltammetry scan of the as-grown structure in $0.1 \mathrm{M} \mathrm{KOH}$ is shown in Fig. 3, curve 1. The potential window of water electrolysis on this AlInN surface was $\approx 3 \mathrm{~V}$. A small peak was observed only in the negative potential range prior to the onset of hydrogen evolution. According to Ref. 21 this peak can be associated with the chemisorption of hydronium ions, which substitute the indium- or aluminium-hydrogen surface bonds. No other activity on the surface was observed within the potential window. The background current was in the $\mathrm{nA} / \mathrm{cm}^{2}$ 
(a)
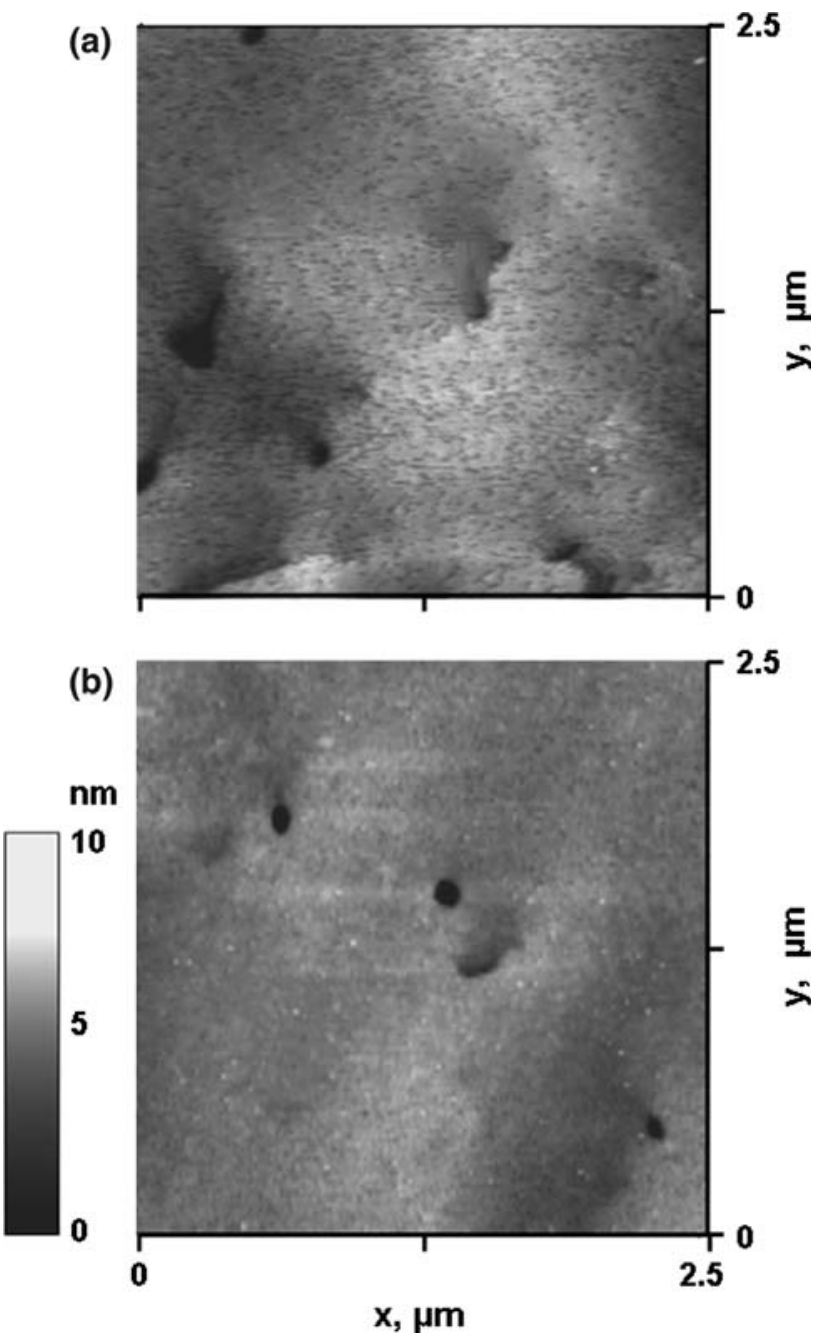

Fig. 2. AFM images: (a) as-grown AllnN surface; (b) after anodic oxidation. The surface roughness (RMS) is approximately $0.8 \mathrm{~nm}$ in both cases.

range, which points towards a high quality of the as-grown surface. Here it should be noted that strong anodic polarization of the as-grown surface led to irreversible changes of its electrochemical and electronic characteristics (discussed below). Therefore all measurements of the as-grown structures discussed here were performed within a limited potential range prior to application of the anodic treatment.

The electrochemical impedance spectroscopy of the as-grown structure indicated the presence of two $R C$ elements in series, as shown in Fig. 4a insert. The corresponding Bode plot measured at $0.0 \mathrm{~V}$ versus $\mathrm{SCE}$ in $0.1 \mathrm{M} \mathrm{KOH}$ is shown in Fig. 4a. The fitting of the impedance spectra was performed using ZSimpWin ${ }^{\circledR}$ data analysis software. Prior to the fitting procedure, the value of the cell series resistance was evaluated and subtracted from the impedance data. The fitting parameters of the equivalent circuit are listed in Table I. The capacitance $C_{1}$ obtained from the fit was approximately

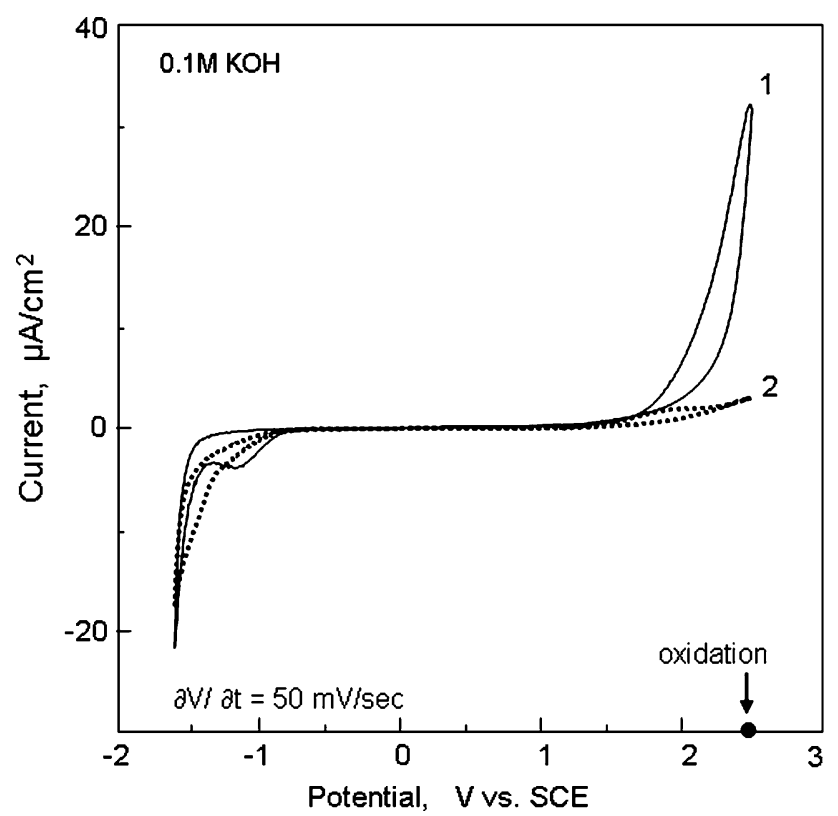

Fig. 3. Linear cyclic voltammetry of the lattice-matched AllnN/GaN heterostructure. Curve 1: as-grown surface (the first scan); curve 2: after strong anodic oxidation with a total charge transfer of about $1 \times 10^{16} \mathrm{~cm}^{-2}$. The potential of the oxidation process is marked by the arrow.

$0.72 \mu \mathrm{F} / \mathrm{cm}^{2}$, which corresponds to the expected AlInN barrier layer capacitance, taking into account its thickness $t$ (10 nm to $12 \mathrm{~nm})$ and dielectric constant $\varepsilon(\sim 10)$. The corresponding parallel resistance $R_{1}$ was in the range of $10 \mathrm{M} \Omega \mathrm{cm}^{2}$, which confirmed the absence of charge transport across this barrier layer in the electrolyte and correlates with the low background current in the voltammogram.

The second $R C$ element was fitted using a constant-phase element (CPE) $Q_{2}$ with the complex admittance $Q_{0}(\mathrm{j} \omega)^{n}$, where $Q_{0}$ and $n$ are parameters and $\omega=2 \pi f$ with frequency $f$, as shown in the inset to Fig. 4 b. The value of the nominal capacitance at $\omega=1$ related to the CPE $Q_{2}$ was $\approx 20 \mu \mathrm{F} / \mathrm{cm}^{2}$, which is typical for an electrical double-layer capacitance on metal electrodes. On the other hand, the as-grown AlInN surface might be characterized by the presence of a native oxide with a thickness of a few monolayers, as demonstrated for the case of AlGaN/GaN heterostructures. ${ }^{19}$ The presence of a chemically active oxide layer on the as-grown surface was supported by measuring the opencircuit potential (OCP) in $0.1 \mathrm{M} \mathrm{H}_{2} \mathrm{SO}_{4}$ and $0.1 \mathrm{M}$ $\mathrm{KOH}$ electrolytes. For the as-grown surface the OCP values were $+0.40 \mathrm{~V}$ and $-0.19 \mathrm{~V}$ versus SCE, respectively. This yielded a $\mathrm{pH}$ sensitivity of $\approx 50 \mathrm{mV} / \mathrm{pH}$, which approaches the theoretical Nernst's limit of $59 \mathrm{mV} / \mathrm{pH}$ and which is typical for oxidized III-nitride surfaces. ${ }^{10}$ Thus, the $R_{2} Q_{2}$ element of the equivalent circuit can be attributed either to the electrical double layer on the AlInN surface or to a native surface oxide. The dispersion factor $n$ of the CPE was about 0.80 , which can be 

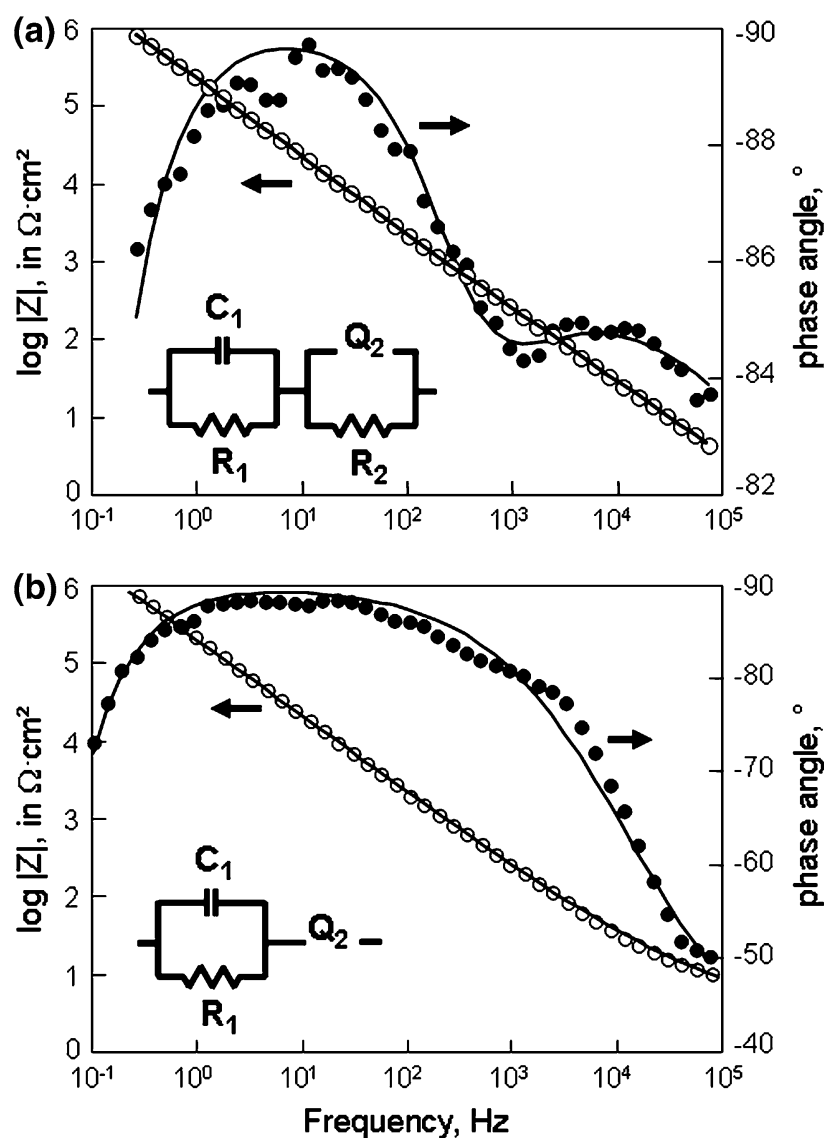

Fig. 4. Bode plots of the AllnN/GaN heterostructure at an electrode potential of $0.0 \mathrm{~V}$ versus SCE in $0.1 \mathrm{M} \mathrm{KOH}$ : (a) as-grown surface; (b) after anodic oxidation. The solid curves show the best fit using the equivalent circuits in the insert. The fitting parameters are listed in Table I.

interpreted in terms of inhomogeneous surface characteristics. ${ }^{22}$

The channel resistance between the source and drain contacts in air was $\approx 253 \Omega$ /square, which is consistent with the sheet carrier density $n_{\mathrm{s}}$ of and the mobility $\mu$ from the Hall measurements. No noticeable changes of the channel resistance were observed when the as-grown structure was dipped into the electrolyte solutions with no external gate electrode connected.

In the FET mode (with the gate electrode biased), the as-grown structure showed a high drain current but a very low transconductance. The corresponding transfer characteristics in $0.1 \mathrm{M} \mathrm{H}_{2} \mathrm{SO}_{4}$ and $0.1 \mathrm{M}$ $\mathrm{KOH}$ are shown in Fig. 5. Both curves showed a $\mathrm{pH}$-induced shift, which is typical for ion-sensitive

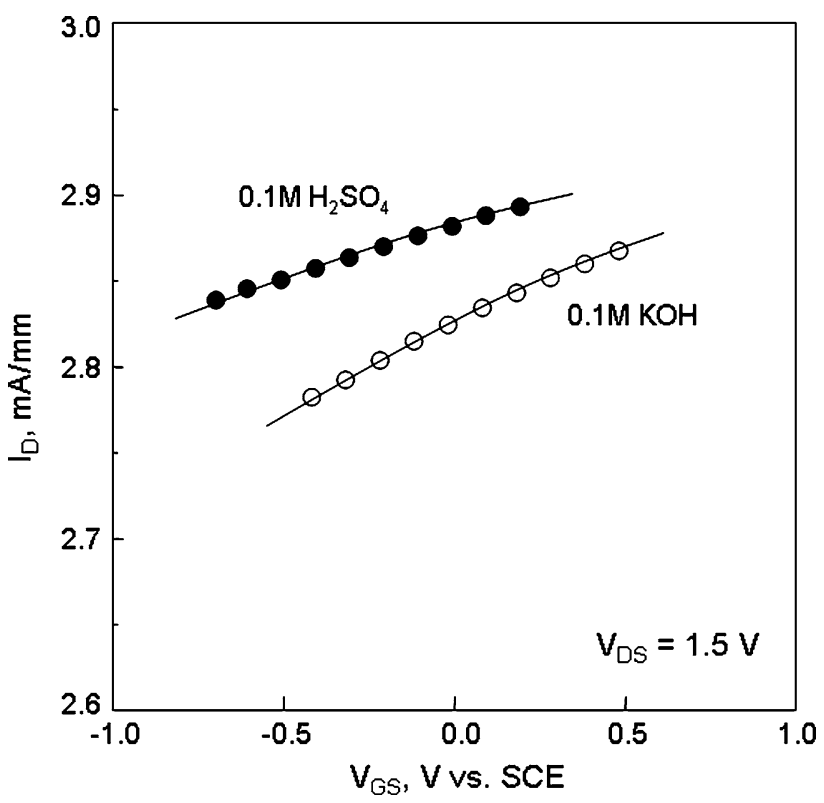

Fig. 5. Transfer characteristics of the as-grown FET structure (before oxidation) in $0.1 \mathrm{M} \mathrm{H}_{2} \mathrm{SO}_{4}$ and $0.1 \mathrm{M} \mathrm{KOH}$ electrolytes at a drain bias $V_{\mathrm{DS}}$ of $1.5 \mathrm{~V}$.

FETs. ${ }^{9-11}$ In our experiments, $\mathrm{pH}$ sensing of the as-grown AlInN surface could be expected as well, regarding the $\mathrm{pH}$-induced shift of the OCP values mentioned above. However, the projected pinch-off voltage estimated from the slope of the transfer characteristics would be about $-6 \mathrm{~V}$ or more. This means that the gate bias range for channel modulation is located at high negative potentials corresponding to the range of oxygen evolution on the AlInN surface (note, that a negative gate potential means a positive potential of the surface in the electrode mode, see Fig. 3). At the low gate potentials corresponding to the window of water electrolysis with low gate leakage current, the as-grown FET operated in the current saturation range. This makes accurate modeling of the FET characteristics impossible.

\section{Effect of Anodic Treatment in KOH Electrolyte}

The effect of anodic treatments was studied by exposing the gate area of the FET in $0.1 \mathrm{M} \mathrm{KOH}$ at a potential of $+2.5 \mathrm{~V}$ versus SCE, as marked in Fig. 3 by the black dot. The amount of charge transferred during the oxidation was about $1.6 \mathrm{mC} / \mathrm{cm}^{2}$ $\left(\sim 1 \times 10^{16}\right.$ electrons $\left./ \mathrm{cm}^{2}\right)$. The cyclic voltammogram

Table I. Fitting Parameters of the Electrochemical Impedance Spectra in Fig. 4

\begin{tabular}{|c|c|c|c|c|c|}
\hline Equiv. Circuit & $\begin{array}{c}C_{1} \\
\mathbf{F} / \mathbf{c m}^{2}\end{array}$ & $\begin{array}{c}R_{1} \\
\Omega \mathrm{cm}^{2}\end{array}$ & $\begin{array}{c}Q_{2:}: Q_{0} \\
\mathrm{~S} \mathrm{~s}^{1 / 2 / \mathbf{c m}^{2}}\end{array}$ & $\begin{array}{c}\mathbf{Q}_{2}: \\
\mathrm{n}\end{array}$ & $\begin{array}{c}R_{1} \\
\Omega \mathrm{cm}^{2}\end{array}$ \\
\hline $\begin{array}{l}\text { (a) } \\
\text { (b) }\end{array}$ & $\begin{array}{l}7.2 \times 10^{-7} \\
7.9 \times 10^{-7}\end{array}$ & $\begin{array}{l}9.8 \times 10^{6} \\
6.2 \times 10^{6}\end{array}$ & $\begin{array}{l}2.0 \times 10^{-5} \\
\sim 6 \times 10^{-4}\end{array}$ & $\begin{array}{l}0.80 \\
0.40\end{array}$ & $\begin{array}{c}9.5 \times 10^{2} \\
-\end{array}$ \\
\hline
\end{tabular}


of the oxidized surface revealed a pronounced suppression of the anodic current (curve 2 in Fig. 3). A similar effect has been reported for $n$-doped $\mathrm{GaN}$ electrodes after anodic treatment in $\mathrm{NaOH}$ electrolyte $^{23,24}$ and has been explained by the formation of a surface oxide. The formation of an oxide layer on the AlInN surface could therefore also be expected in our experiments. However, no changes of the surface morphology were revealed after the oxidation. The AFM image of the treated surface is shown in Fig. 2b. No traces of corrosion, such as an increased surface roughness or a change of the dislocation areas, were revealed in comparison to the as-grown surface.

However, the impedance characteristics of the AlInN-electrolyte interface were noticeably changed after the oxidation. The corresponding Bode plot is shown in Fig. 4b. The impedance spectrum was fitted now by a circuit consisting of an $R_{1} C_{1}$ element and a single CPE $Q_{2}$ in series (Fig. $4 \mathrm{~b}$, inset). The dispersion factor $n$ of the CPE was reduced after the oxidation treatment to about 0.4 , while its numerical value at $\omega=1$ was increased by a factor of 30 in comparison to the as-grown condition (see Table I). According to Ref. 25 a CPE with such a low value of $n$ could be explained by a distributed $R C$ network, which describes an inhomogeneous system. The parameters of the $R_{1} C_{1}$ element representing the AlInN surface barrier layer were slightly changed after the oxidation. The capacitance $C_{1}$ obtained from the best fit was increased by $9 \%$ from $0.72 \mu \mathrm{F} / \mathrm{cm}^{2}$ to $\approx 0.79 \mu \mathrm{F} / \mathrm{cm}^{2}$ at $0.0 \mathrm{~V}$ potential in $0.1 \mathrm{M} \mathrm{KOH}$. The corresponding parallel resistance $R_{1}$ was reduced by $40 \%$, but was still remaining in the $\mathrm{M} \Omega \mathrm{cm}^{2}$ range. Similar changes of the equivalent circuit parameters were observed also at other potentials both in $0.1 \mathrm{M} \mathrm{KOH}$ and $0.1 \mathrm{M} \mathrm{H}_{2} \mathrm{SO}_{4}$ electrolytes.

The anodic treatment also led to a partial depletion of the $2 \mathrm{D}$ channel. The sheet resistance within the oxidized area was increased to $6.9 \mathrm{k} \Omega /$ square. The pinch-off voltage of the FET structures exposed to the electrolytes was shifted into the potential window with low gate leakage current. This enabled the full analysis of the FET characteristics. The direct-current (DC) output characteristics of the oxidized FET in $0.1 \mathrm{M} \mathrm{H}_{2} \mathrm{SO}_{4}$ and the corresponding transfer characteristics in the saturation range in $0.1 \mathrm{M} \mathrm{H}_{2} \mathrm{SO}_{4}$ and $0.1 \mathrm{M} \mathrm{KOH}$ are shown in Fig. 6 . The FET characteristics were analyzed using a charge-control model of a metal-insulator-semiconductor FET (MISFET) here applied to a heterostructure FET. ${ }^{26}$ This model was adapted to our structures by taking into account the results of the impedance analysis of the electrolyte-heterostructure interface. Since the CPE $Q_{2}$ showed a high nominal value, its effect on the gate capacitance $C_{\mathrm{GS}}$ in the DC mode could be ignored. Thus, the $C_{\mathrm{GS}}$ value in the MISFET model was taken equal to the $C_{1}$ element, which is $0.79 \mu \mathrm{F} / \mathrm{cm}^{2}$. This value was also close to the expected capacitance of the AlInN
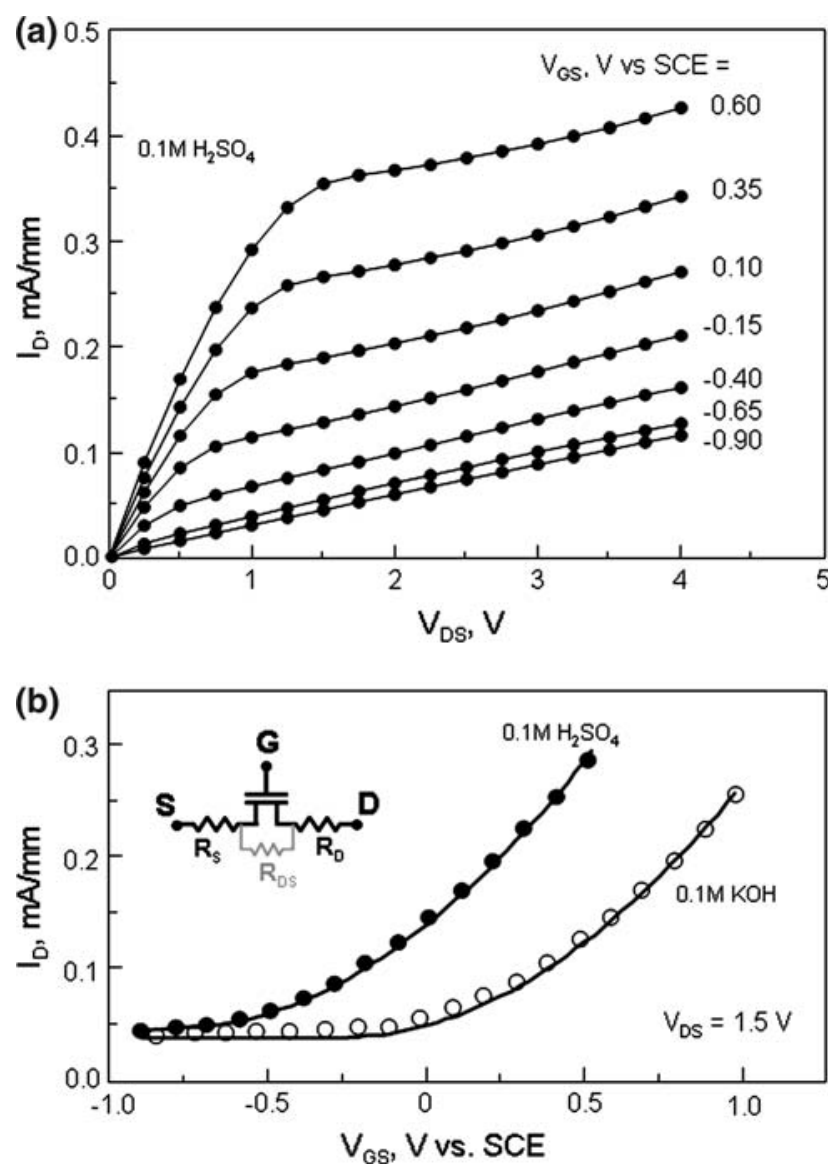

Fig. 6. (a) The output characteristics of the ion-sensitive FET (ISFET) with the gate length $L_{G}$ of $0.5 \mathrm{~mm}$ in $0.1 \mathrm{M} \mathrm{H}_{2} \mathrm{SO}_{4}$ and (b) the corresponding transfer characteristics in $0.1 \mathrm{M} \mathrm{H}_{2} \mathrm{SO}_{4}$ and $0.1 \mathrm{M} \mathrm{KOH}$ at the drain bias of $1.5 \mathrm{~V}$. The solid curves in (b) are the fits from a MISFET model. The equivalent circuit model including the parasitic resistance of the channel $R_{\mathrm{DS}}$ is shown in the inset (see text).

barrier layer. In addition, the series resistance of the source and drain areas (formed by the part of the channel covered with the adhesive tape) $R_{\mathrm{S}}$ and $R_{\mathrm{D}}$ of $150 \Omega$ were also taken into account. To fit the data close to the pinch-off, a parallel source-to-drain shunt resistance $R_{\mathrm{DS}}$ of $20 \mathrm{k} \Omega$ was also included into the model (see Fig. 6b inset). The fitting of the transfer characteristics by the MISFET model is shown in Fig. $6 \mathrm{~b}$ by the solid curves. The pinch-off voltages derived from this fit were $-0.80 \mathrm{~V}$ versus $\mathrm{SCE}$ in $0.1 \mathrm{M} \mathrm{H}_{2} \mathrm{SO}_{4}$ and $-0.25 \mathrm{~V}$ versus $\mathrm{SCE}$ in $0.1 \mathrm{M} \mathrm{KOH}$. The pH-induced shift of the transfer characteristics correlated with the $\mathrm{pH}$-dependent open-circuit potential in these electrolytes equal to $+0.40 \mathrm{~V}$ and $-0.17 \mathrm{~V}$ versus SCE, respectively.

The fitted value of the carrier mobility in the FET channel was about $200 \mathrm{~cm}^{2} / \mathrm{V} \mathrm{s}$, compared to $950 \mathrm{~cm}^{2} / \mathrm{V} \mathrm{s}$ of the as-grown structure. Taking the value of the sheet resistance of $6.9 \mathrm{k} \Omega /$ square in air, the sheet charge density within the exposed area of the heterostructure was estimated to be $\approx 4.5 \times 10^{12} \mathrm{~cm}^{-2}$. To understand the origin of the depletion effect by the anodic treatment, the energy 
(a)
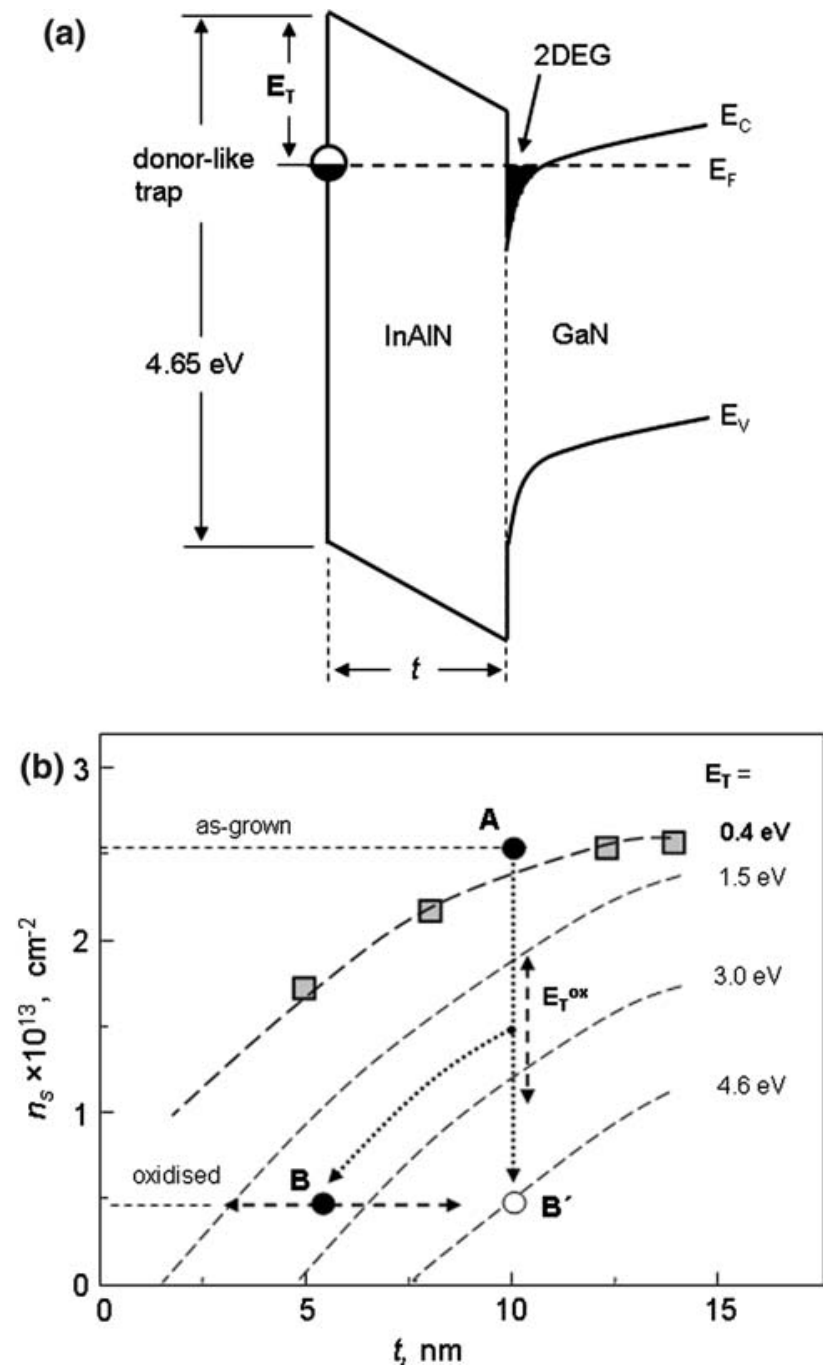

Fig. 7. (a) Schematic band diagram of the AllnN/GaN heterostructure and (b) the 2DEG density calculated for various thicknesses $t$ of the barrier layer and energy levels $E_{\mathrm{T}}$ of the surface traps by $2 \mathrm{D}$ numerical simulation (dashed lines). The square symbols show the data points from Ref. 20 on the lattice-matched AllnN/GaN heterostructures (as-grown layers) with various barrier thicknesses $t$. The symbols $A, B$, and $B^{\prime}$ are explained in the text.

band diagram of the AlInN/GaN heterostructure was analyzed using 2D numerical simulation $\left(\right.$ Silvaco $\left.{ }^{\circledR}\right)$. A schematic band diagram of the heterostructure is shown in Fig. 7a, including the polarization effects of the GaN-based material system. The polarization-induced charge at the AlInN/ GaN interface was calculated using the theoretical model in Ref. 27. The parameters of this model were adjusted to the material properties of the AlInN barrier, the GaN buffer, and the conduction-band offset $\Delta E_{\mathrm{C}}$ of $0.91 \mathrm{eV}$ at the AlInN/GaN interface. ${ }^{28}$ In the 2D energy-band model the polarizationinduced field was simulated by a dipole charge of $2.6 \times 10^{13} \mathrm{~cm}^{-2}$ at the opposite surfaces of the AlInN barrier layer. The two-dimensional electron gas (2DEG) can be considered to be generated by a surface donor state. ${ }^{29}$ The positive charge accumulated at this surface donor state will balance the 2DEG density in the channel, whereas the energy level of this surface state will determine the filling of the 2D channel at the heterostructure interface. Following this concept, we introduced a donor-like surface state in the 2D simulation model to represent the surface donor. The energy level and the density of the surface state on the as-grown surface were evaluated using the experimental dependence of the 2DEG density on the thickness of the AlInN barrier layer as reported in Ref. 20, AlInN/GaN heterostructures have been grown with different barrier thicknesses using the same MOCVD process as in our study. Figure $7 \mathrm{~b}$ shows the calculated dependencies of the 2DEG density $n_{\mathrm{S}}$ as a function of the barrier layer thickness $t$ and the donor level energy $E_{\mathrm{T}}$ (dashed curves). The experimental data points from Ref. 20 are shown in Fig. $6 \mathrm{~b}$ by the square symbols. By fitting these data, an energy level of the surface donor $E_{\mathrm{T}}$ at about $0.4 \mathrm{eV}$ below the conduction band was found. The value of $n_{\mathrm{s}}$ for the as-grown structure in our experiment, as marked by the symbol $\mathrm{A}$, is also in close agreement with this trap energy level.

However, the $n_{\mathrm{S}}$ value of $4.5 \times 10^{12} \mathrm{~cm}^{-2}$ after the oxidation cannot be explained by any reasonable trap level within the bandgap, provided the barrier thickness $t$ remains $10 \mathrm{~nm}$ of the as-grown surface. This scenario is shown in Fig. 7b, where the dotted arrow connecting the points A and $\mathrm{B}^{\prime}$ illustrates the shift of $n_{\mathrm{S}}$ induced by a surface state level only. As one can see, this energy level would be located below the valence-band edge, which is not realistic. A more reasonable explanation of the observed effect would be a reduction of the AlInN barrier layer thickness by oxidation. Such a scenario is shown in Fig. 7b by the broken dotted arrow connecting the points $\mathrm{A}$ and $\mathrm{B}$. The exact thickness of the reduced barrier according to this model could be estimated by knowing the energy level $E_{\mathrm{T}}^{\text {ox }}$ of the oxidationinduced states, as shown on the graph. But since no reliable data on the $E_{\mathrm{T}}^{\text {ox }}$ value are available up to now, no further details of the barrier composition can be determined yet. From the tunnelling limit of the AlInN barrier thickness ( 1 nm to $2 \mathrm{~nm})$, the oxidation-induced traps might be located at any energy level below $1 \mathrm{eV}$ to $1.5 \mathrm{eV}$ from the conduction-band edge, as shown by the dashed horizontal and vertical arrows in Fig. 7b.

On the other hand, the capacitance $C_{1}$ attributed to the barrier layer did not change essentially during the oxidation treatment, as revealed by the impedance spectroscopy measurements in Fig. 4b (also see Table I). This may be explained by a surface oxide layer, which substituted electrically a part of the barrier layer lost during the anodic oxidation treatment. Such explanation means bulk oxidation of the AlInN material rather than etching. In this case the insulating layer between the $2 \mathrm{D}$ channel and the surface would be a two-layer structure consisting of 
the thinner AlInN barrier layer and the native oxide layer on top. Here it is important to note that the value of $n_{\mathrm{s}}$ is determined by the thickness of the polar AlInN layer, but not by the thickness of the nonpolar oxide. Therefore, the bulk oxidation would lead to a reduction of $n_{s}$, but not to a significant change of the capacitance. However, no evidence of a separate $R C$ element related to the surface oxide layer could be resolved by the electrochemical impedance spectroscopy, which was limited to the frequency range below $100 \mathrm{kHz}$. This might be explained by a compact structure of the oxide with negligible diffusion of ions from the electrolytes.

The proposed model may also explain the reduction of the mobility in the 2D channel after the oxidation. According to the model of carrier scattering in 2DEG systems, ${ }^{30}$ the reduction of the insulating barrier separating the 2DEG and the charged stated at the oxidized interface would increase scattering at the remote ionized states. But no data on the preferential location of the oxidationinduced traps could be given yet. More study is needed to identify this oxide layer and its chemical composition.

\section{CONCLUSIONS}

In this paper we have described the effect of anodic treatments on the electronic characteristics of AlInN/GaN heterostructures. The grown heterostructure material was lattice-matched with about $17 \%$ indium content in the barrier layer. The carrier mobility in the $2 \mathrm{D}$ channel was $950 \mathrm{~cm}^{2} / \mathrm{V}$ s and the $2 \mathrm{DEG}$ density was $2.6 \times 10^{13} \mathrm{~cm}^{-2}$. For the analysis, we prepared a set of field-effect transistor structures with open gate areas in direct contact with electrolyte solutions. Such structures enabled us to analyze the electrical equivalent circuit of the AlInN-electrolyte interface by electrochemical impedance spectroscopy in the electrode mode, the electronic characteristics of the heterostructure in the ion-sensitive FET mode, and to trace the evolution of these characteristics after the surface oxidation by in situ anodic treatment in $0.1 \mathrm{M} \mathrm{KOH}$ electrolyte. The obtained results were used to analyze the energy band structure of the AlInN/GaN heterostructures by 2D numerical simulation.

It was found that a strong anodic treatment of the heterostructure with the total charge transfer of $10^{16}$ electrons $/ \mathrm{cm}^{2}$ most likely induced bulk oxidation of the AlInN barrier layer rather than etching. The oxidized barrier layer may represent a twolayer structure consisting of a thinned AlInN barrier and the oxide layer on top. The electrical resistance across this surface oxide layer in electrolytes was as high as the resistance across the AlInN barrier layer. This may suggest a compact structure of the oxide with negligible diffusion of ions from the electrolytes. No traces of the surface corrosion or selective etching by oxidation was revealed by AFM.
The Fermi level at the oxidized barrier surface was pinned deep (up to several eV energy) in the bandgap of AlInN. In comparison, the location of the surface Fermi level on the as-grown heterostructure was estimated to be about $0.4 \mathrm{eV}$ below the conduction-band edge of AlInN. The oxidation-induced states reduced the 2DEG density in the channel to approximately $4.5 \times 10^{12} \mathrm{~cm}^{-2}$. The carrier mobility in the 2D channel was also reduced by approximately a factor of 5 , most likely due to enhanced scattering on the charged surface/interface states. Also, the oxidation-induced depletion shifted the characteristics of the electrolyte-gate FET into the gate potential range corresponding to the low gate leakage across the heterostructure-electrolyte interface.

However, the data on the chemical composition of the oxidized surface are still missing. A better understanding of the surface characteristics and the oxidation mechanisms might lead to improvement of the surface oxidation technology. The stable surface oxides of the AlInN/GaN heterostructures could be used in chemical sensor devices and for surface passivation of microwave power HEMT structures.

\section{ACKNOWLEDGEMENTS}

This work was supported by the European Project UltraGaN (co. \#6903). The authors would like to thank D.M. Kolb (Inst. of Electrochemistry, Ulm University) for helpful discussions.

\section{REFERENCES}

1. M. Gonschorek, J.-F. Carlin, E. Feltin, M.A. Py, and N. Grandjean, Appl. Phys. Lett. 89, 062106 (2006).

2. J. Kuzmik, A. Kostopoulus, G. Konstantinidis, J.-F. Carlin, A. Georgakilas, and D. Pogany, IEEE Trans. Electron. Dev. $53,422(2006)$.

3. K. Lorenz, N. Franco, E. Alves, I.M. Watson, R.W. Martin, and K. O'Donnnell, Phys. Rev. Lett. 97, 85501 (2006).

4. F. Medjdoub, J.F. Carlin, M. Gonschorek, E. Feltin, M.A. Py, D. Ducatteaux, C. Gaquiere, N. Grandjean, and E. Kohn, IEDM Techn. Dig. 927 (2006).

5. A. Gadanecz, J. Bläsing, A. Dadgar, C. Hums, and A. Krost, Appl. Phys. Lett. 90, 221906 (2007).

6. J. Dorsaz, H.J. Bühlmann, J.F. Carlin, N. Grandjean, and M. Ilegems, Appl. Phys. Lett. 87, 072102 (2005).

7. F. Rizzi, K. Bejtka, P.R. Edwards, R.W. Martin, and M. Watson, J. Cryst. Growth 300, 254-258 (2007).

8. E. Miller, D. Schaadt, E.T. Yu, P. Waltereit, C. Poblenz, and J. Speck, Appl. Phys. Lett. 82, 1293 (2003).

9. G. Steinhoff, M. Herrmann, W.J. Schaff, L.F. Eastman, M. Stutzmann, and M. Eickhoff, Appl. Phys. Lett. 83, 177 (2003).

10. N. Chaniotakis, Y. Alifragis, A. Georgakilas, and G. Konstantinidis, Appl. Phys. Lett. 86, 164103 (2005).

11. M. Stutzmann, G. Steinhoff, M. Eickhoff, O. Ambacher, C.E. Nebel, J. Schalwig, R. Neuberger, and G. Müller, Diam. Relat. Mater. 11, 886 (2002).

12. H. Lu, W. Schaff, and L. Eastman, J. Appl. Phys. 96, 3577 (2004).

13. C. Baratto, M. Ferroni, G. Faglia, and G. Sberveglieri, Sensors Actuators B 118, 221 (2006).

14. B. Baur, G. Steinhoff, J. Hernando, O. Purrucker, M. Tanaka, B. Nickel, M. Stutzmann, and M. Eickoff, Appl. Phys. Lett. 87, 263901 (2005) 
15. C. Vartuli, S. Pearton, J. Lee, C. Abernathy, J. Mackenzie, J. Zopler, R. Shul, and R. Ren, J. Electrochem. Soc. 143, 3681 (1996).

16. S. Smith, C. Wolden, M. Bremser, A. Hanser, R. Davies, and W. Lampert, Appl. Phys. Lett. 71, 3631 (1997).

17. J. Mileham, S. Pearton, C. Abernathy, J. MacKenzie, R. Shul, and S. Kilcoyne, Appl. Phys. Lett. 67, 1119 (1997).

18. O. Weidemann, M. Hermann, G. Steinhoff, H. Wingbrant, A. Lloyd Spetz, M. Stutzmann, and M. Eickoff, Appl. Phys. Lett. 83, 773 (2003).

19. T. Hashizume, S. Ootomo, R. Nakasaki, S. Oyama, and M. Kihara, Appl. Phys. Lett. 76, 2880 (2000).

20. F. Medjdoub, J.-F. Carlin, M. Gonschorek, E. Feltin, M.A. Py, M. Knez, D. Troadec, C. Gaquiere, A. Chuvilin, U. Kaiser, N. Grandjean, E. Kohn, DRC Tech. Dig. 109 (2007).

21. N. Asai, Y. Inoue, H. Sugimura, and O. Takai, J. Electrochem. Soc. 146, 2365 (1999).
22. C.-H. Kim, S.-I. Pyun, and J.-H. Kim, Electrochim. Acta 48, 3455 (2003).

23. M. Ohkubo, Jpn. J. Appl. Phys. 36, L955 (1997).

24. I. Huygens, K. Strubbe, and W.P. Gomes, J. Electrochem. Soc. 147, 1797 (2000).

25. J. Bisquert, J. Phys. Chem. 2, 4185 (2000).

26. F. Ali and A. Gupra, eds., HEMTs and HBTs: Devices, Fabrication and Circuits (Artech House: Boston, London, 1991), $377 \mathrm{pp}$.

27. O. Ambacher, J. Majewski, C. Miskys, A. Link, M. Hermann, M. Eickhoff, M. Stutzmann, F. Bernardini, V. Fiorentini, V. Tilak, B. Schaff, and L.F. Eastmam, J. Phys. Condensed Matter 14, 3399 (2002).

28. J. Kuzmik, Semicond. Sci. Technol. 17, 540 (2002).

29. J.R. Ibbetson, P.T. Fini, K.D. Ness, S.P. DenBaars, and J.S. Speck, U.K. Mishra Appl. Phys. Lett. 77, 250 (2000).

30. K. Lee, M.S. Shur, T.J. Drummond, and H. Morkoc, J. Appl. Phys. 54, 6432 (1983). 